\title{
Effects of Envy on Depression: The Mediating Roles of Psychological Resilience and Social Support
}

\author{
Yanhui Xiang ${ }^{1,2^{\star} \bowtie}$, Xia Dong ${ }^{1,2^{\star}}$, and Jiaxu Zhao ${ }^{1,2}$ \\ ${ }^{1}$ Department of Psychology, Hunan Normal University, Changsha, China \\ ${ }^{2}$ Cognition and Human Behavior Key Laboratory of Hunan Province, Hunan Normal University, Changsha, China
}

Objective Envy, as a stable personality trait, can affect individuals' mental health. Specifically, previous studies have found that envy can lead to depression; however, the mechanism by which envy affects depression is still unclear. Therefore, based on the resilience framework, we used structural equation modeling to explore the mediating roles that social support and psychological resilience play between envy and depression.

Methods Chinese college students $(n=680)$ were recruited to complete four scales: the Dispositional Envy Scale (DES), the Symptom Checklist 90-Depression Subscale (SCL-90-DS), the Connor-Davidson Resilience Scale (CD-RISC), and the Perceived Social Support Scale (PSSS).

Results The results confirmed that both social support and psychological resilience are significant mediators between envy and depression. Furthermore, social support plays a significant mediating role between envy and psychological resilience, and psychological resilience plays a significant mediating role between social support and depression. Specifically, the results indicated that envy not only directly increases the likelihood of developing depression, but also indirectly increases the likelihood of developing depression by affecting psychological resilience through negatively influencing social support.

Conclusion This study provides a theoretical basis for enhancing psychological resilience and social support in order to ameliorate adverse effects of envy on depression.

Psychiatry Investig 2020;17(6):547-555

Key Words Envy, Social support, Psychological resilience, Depression.

\section{INTRODUCTION}

In recent years there has been an upsurge in research into depression. Studies have shown that the occurrence and development of depression is affected by many factors, such as genetic factors, ${ }^{1}$ social and family factors, ${ }^{2}$ and even personality traits. ${ }^{3}$ Envy is one such stable personality trait. ${ }^{4-8}$ Individuals with high envy will be more likely to experience inferiority and feelings of ill will, ${ }^{4,89-11}$ thereby affecting their mental health. Meanwhile, previous studies have shown a significant positive correlation between envy and depression. ${ }^{12-15}$ However, the mechanism by which envy affects depression is still unclear.

Received: October 6, 2019 Revised: December 25, 2019

Accepted: March 2, 2020

$\square$ Correspondence: Yanhui Xiang, MD, PhD

Cognition and Human Behavior Key Laboratory of Hunan Province, Hunan Normal University, Changsha 410081, China

Tel: +86-73188873076, E-mail: xiangyh@hunnu.edu.cn

*These authors contributed equally to this work.

(a) This is an Open Access article distributed under the terms of the Creative Commons Attribution Non-Commercial License (https://creativecommons.org/licenses/bync/4.0) which permits unrestricted non-commercial use, distribution, and reproduction in any medium, provided the original work is properly cited.
Therefore, it is very meaningful to explore this mechanism in order to expand the understanding of the mechanism of depression formation from the perspective of envy.

Interestingly, envy has been shown to be negatively correlated with social support. ${ }^{16}$ Social support is an external supporting resource that can also inhibit depression. ${ }^{17-19}$ In addition, contrary to envy, which is associated with negative characteristics, ${ }^{8,20}$ psychological resilience is a protective mechanism associated with positive characteristics. ${ }^{21}$ Moreover, previous studies have pointed out that psychological resilience can inhibit the occurrence of depression. ${ }^{22,23}$ Therefore, the present study aims to explore the mediating roles of social support and psychological resilience between envy and depression based on the resilience framework theory. The research not only extends the resilience framework theory, but also provides a new practical perspective for the prevention and treatment of the impact of envy on depression.

\section{The relationship between envy and depression}

Depression is an individual's negative view of the self, the 
world, and the future, as well as uncontrollable and frequent negative thoughts, ${ }^{24}$ characterized by pessimism, self-denial, compliance, and self-accusation. ${ }^{25,26}$ Research shows that personality traits are one of the influencing factors of depression. ${ }^{3}$ Envy is one such personality trait; ${ }^{4-8}$ people with high envy levels are more sensitive to information in social comparisons, thus leading to feelings of individual inferiority, resentment, hostility, and so on. ${ }^{4,8,11}$ Social comparison theory states that people generally choose to compare themselves with others who are close to their own abilities and opinions; ${ }^{27}$ however people generally perceive themselves to be better than they objectively are. ${ }^{28}$ Therefore people tend to make upward social comparisons, that is, compare themselves to those who are actually more able, have more possessions, and so forth. ${ }^{29}$ Individuals with high levels of envy will find these differences more salient and face more negative experiences as a result. ${ }^{8,11}$ These include feelings of inferiority and dejection, which may lead to depression. ${ }^{12}$ Moreover, some empirical studies have indicated a positive correlation between envy and depression. ${ }^{13-15}$ Based on the literature, this study also hypothesizes that envy can positively predict depression.

\section{The mediating effect of psychological resilience and social support}

Psychological resilience can be defined as a tendency to overcome and actively adjust to adversities and stress. ${ }^{30}$ It includes tenacity, self-efficacy, tolerance of negative affect, and other internal protection factors. ${ }^{21,31}$ According to the resilience framework, when people face stressors and challenges, the interaction between their external environment and psychological resilience will affect how well they adapt to adversity. ${ }^{32}$ If people do not adapt well, they may experience depression. ${ }^{33}$ Therefore, psychological resilience may be the explanatory mechanism of envy and depression. Moreover, some studies have shown that negative personality traits can negatively affect selfefficacy, ${ }^{34,35}$ one of the characteristics of psychological resilience. ${ }^{31}$ Envy is a negative personality trait, ${ }^{4}$ thus envy may reduce self-efficacy. As such, we hypothesized that envy may negatively affect psychological resilience. In addition, numerous studies have reported a negative correlation between psychological resilience and depression..$^{17,36,37}$ Therefore, people with high levels of envy may have lower levels of psychological resilience, which may in turn increase depression. Based on the above evidence, we further hypothesized that psychological resilience plays a mediating role in envy and depression.

Social support refers to the spiritual and material support, including love, care, and respect, that individuals obtain from social relations such as family, colleagues, groups, organizations, and communities. ${ }^{38}$ This support can alleviate people's psychological stress response, relieve their nervous state, and improve their social adaptability. ${ }^{39}$ In addition, based on the resilience framework, ${ }^{32}$ when people face stressors and challenges, external support resources from family, society, and peers interact with internal psychological resilience factors. When people face negative experiences, they perceive less external social support resources which lowers the level of psychological resilience, lead to maladjustment, ${ }^{32}$ and may ultimately lead to depression. ${ }^{33}$ Moreover, previous research has discussed the relationship between envy and social support. Such as Xiang et al., ${ }^{16}$ who reported a negative correlation between envy and social support. The mechanism may be that envy can lead to cheating ${ }^{40}$ and aggressive behaviors, ${ }^{41}$ which may damage that individual's interpersonal relationships and make them less likely to perceive and accept social support. ${ }^{42}$ In addition, many studies have shown that there is a negative correlation between social support and depression. ${ }^{43-48}$ Thus people with high levels of envy may perceive less social support, which may increase depression. Therefore, social support may also be an explanatory mechanism for envy and depression. Based on the above analyses, we hypothesized that social support plays a mediating role in the influence of envy on depression.

Furthermore, according to the resilience framework, when people face stressors and challenges, ${ }^{32}$ the lower the external support resources, the lower the individual's psychological resilience will be which will lead to the individual's negative adaptation to adversity. ${ }^{49,50}$ Furthermore, people with high levels of envy may perceive less social support compared to their peers, leading to lower levels of psychological resilience, which may increase depression. For these reasons, we further hypothesized that envy may also negatively affect psychological resilience through its negative influence social support, thereby indirectly increasing depression.

\section{The present study}

The present study aims, based on the resilience framework, to explore the mediating mechanisms of social support and psychological resilience in the relationship between envy and depression. Based on the literature described above, we proposed four hypotheses: 1 ) there is a significant positive correlation between envy and depression. 2) There is a significant negative correlation between envy and psychological resilience. 3) Social support and psychological resilience both play significant roles in mediating envy and depression. 4) Envy may also negatively affect psychological resilience through its negative influence social support, thereby indirectly increasing depression. 


\section{METHODS}

\section{Participants and procedures}

In the study, 680 participants were recruited by random sampling method and cluster sampling method, including 186 men and 494 women. The average age were $19.16 \pm 2.39$ years, and the age range was 17 to 26 years. All the participants were recruited from South China Normal University, Jinan University, South China University of Technology, and Hunan Normal University. None of the participants had any physical or mental health problems. The study was approved by the Institutional Review Board for the Academic Committee of the School of Psychology of Hunan Normal University. The study was approved by the Institutional Review Board for the Academic Committee of the School of Psychology of Hunan Normal University (Approval number: 076). In addition, it should be noted that as our questionnaire collection work is carried out in several batches, about 20 researchers have participated in this questionnaire collection work successively.

A series of questionnaires were completed in the form of group test, including four questionnaires needed in this study, the Dispositional Envy Scale (DES), the Symptom Checklist 90-Depression Subscale (SCL-90-DS), the Connor-Davidson Resilience Scale (CD-RISC) and the perceived social support scale (PSSS), as well as brief demographics. The questionnaires used were all in Chinese. The whole process took approximately 40 minutes. Participants all signed the written informed consent forms before participating in the study and were paid upon completion of the whole questionnaires. In addition, we have two exclusion criteria. First, if all questions had the same answer, we think the participant did not answer them seriously, so we can exclude this questionnaires. Second, if more than $2 / 3$ of the questions were not filled out, we considered excluding it. None of the respondents met the second criteria. In addition, numerous studies have shown the effectiveness of this procedures. ${ }^{51-54}$

\section{Measures}

\section{Dispositional Envy Scale (DES)}

The Dispositional Envy Scale (DES) was proposed by Smith et al. ${ }^{8}$ to evaluate envy. In this study, we used the Chinese version, which has good reliability and validity (Cronbach's $\alpha=$ 0.79). ${ }^{55}$ The scale consists of 8 items (e.g." "I feel envy every day." and "The bitter truth is that I generally feel inferior to others."), and each item is scored on a 5-point Likert scale (1=strongly disagree, $5=$ strongly agree). Higher scores mean a stronger tendency to experience envy. In this study, the scale was internally consistent and its Cronbach's alpha coefficient was 0.77 .

\section{Perceived Social Support Scale (PSSS)}

The Perceived Social Support Scale (PSSS) contains 12 items which were divided into three subscales: family support, friend support, and other support. ${ }^{56}$ Examples of items are: "I can get emotional help and support from my family when I need it" (family support); "My friends can really help me" (friend support); "Some people (leaders, relatives, colleagues) will appear beside me when I encounter problems" (other support). Items are scored on a 7-point Likert scale with higher scores indicating higher levels of social support (1=strongly disagree, $7=$ strongly agree). We used the adaptation of Kong et al. ${ }^{57}$ to evaluate respondents' level of social support because it has shown high reliability and validity in Chinese samples. In the present study, the Cronbach's alpha coefficient of this scale was 0.90 .

\section{Connor-Davidson Resilience Scale (CD-RISC)}

There are 10 items in the Connor-Davidson Resilience Scale (CD-RISC), each scored on a 6-point Likert-type Scale (1= almost agree, $6=$ almost disagree); higher scores indicate higher level of psychological resilience. Examples of items are: "I can deal with whatever comes" and "I can achieve goals despite obstacles". Campbell-sills and Stein ${ }^{21}$ compiled the scale and Kong et al. ${ }^{58}$ proved the reliability of the scale in Chinese samples (Cronbach's $\alpha=0.85$ ). In this study, this scale exhibited adequate reliability $(\alpha=0.90)$.

\section{Symptom Checklist 90-Depression Subscale (SCL-90-DS)}

The Symptom Checklist 90-Depression Subscale (SCL-90DS) has 90 items and ten dimensions and is used to evaluate the depression tendency of individuals. ${ }^{59}$ Items are scored using a 5 -point Likert-type scale ( $0=$ no, $4=$ serious); higher scores indicate higher levels of depression. In this study, the adapted version by Tang and Cheng ${ }^{60}$ was used, which has been proved to have high reliability and validity in Chinese populations. In this study, the reliability of the depression subscale was 0.89 .

\section{Data analysis}

First, we used Amos 22.0 to evaluate the measurement model we built and to test whether our indicators were good predictors of latent variables. We separated the three subscales of social support, divided psychological resilience and depression into three parts, and divided envy into two parts as indicators of factors that use an item-to-construct balance approach. ${ }^{61}$ Once the measurement model was fitted, we established a structural model and selected chi-square statistic, comparative fitting index (CFI), root-mean-square error of approximation (RMSEA), and standardized root-mean-square residual (SRMR) as indicators to test the goodness of fit of 
the model. ${ }^{62}$ At the same time, akaike information criterion (AIC) was used as an indicator of the most suitable model; smaller values mean better fit. ${ }^{63}$ What's more, we used the expected cross validation index (ECVI) as an indicator to assess the replication potential of the model; smaller values indicate greater potential replication. ${ }^{64}$ In addition, we used Bootstrap estimation procedures to test the mediating effects of social support and psychological resilience between envy and depression. Finally, we tested for gender differences,

Table 1. Descriptive statistics and zero-order correlations for all measures

\begin{tabular}{lrrclll}
\hline \multicolumn{1}{c}{ Measrue } & \multicolumn{1}{c}{ M } & \multicolumn{1}{c}{ SD } & 1 & 2 & 3 & 4 \\
\hline 1 Envy & 17.30 & 5.87 & 1.000 & & & \\
2 PSS & 8.76 & 7.85 & $-0.284^{* * *}$ & 1.000 & & \\
3 PR & 62.39 & 11.17 & $-0.446^{* * *}$ & $0.300^{* * *}$ & 1.000 & \\
4 Depression & 34.92 & 5.67 & $0.467^{* * *}$ & $-0.289^{* * *}$ & $-0.351^{* * *}$ & 1.000
\end{tabular}

*** $<<0.001$. PSS: perceived social support, PR: psychological resilience

Table 2. Fit indices model 1

\begin{tabular}{cccccccc}
\hline & $\chi^{2}$ & df & RMSEA & SRMR & CFI & AIC & ECVI \\
\hline Model 1 & 77.994 & 38 & 0.039 & 0.028 & 0.990 & 133.994 & 0.197 \\
\hline
\end{tabular}

RMSEA: root-mean-square error of approximation, SRMR: standardized root-mean-square residual, CFI: comparative fit index, AIC: akaike information criterion, ECVI: expected cross-validation index

\section{RESULTS}

\section{Measurement model}

The latent variables in the measurement model include envy, social support, psychological resilience, and depression. The results showed that the data was very suitable for the measurement model $\left[\chi_{(38,680)}^{2}=77.994, \mathrm{p}<0.001 ; \mathrm{RMSEA}=0.039\right.$; $\mathrm{SRMR}=0.028$; $\mathrm{CFI}=0.990]$. The factor loadings of all potential variables were significantly correlated $(\mathrm{p}<0.001)$, which means that the observed variables represented the latent variables well. In addition, as shown in Table 1, all variables were significantly correlated. Table 1 also contains the mean and standard deviation, as well as the correlations between envy, social support, psychological resilience, and depression.

\section{Structure model}

In order to verify our hypothesis, we built Model 1. In this model envy directly predicts depression and also indirectly influences depression through social support and psychological resilience. The results showed that the indicators were well matched (Table 2) $\left[\chi^{2}{ }_{(38,680)}=77.994, \mathrm{p}<0.001 ; \mathrm{RMSEA}=0.039\right.$; $\mathrm{SRMR}=0.028$; $\mathrm{CFI}=0.990]$. Based on these, we used Model 1 as the final model (Figure 1).

\section{The significance test of mediating variables}

We used Bootstrap estimation procedures to explore the stability of the mediation variables. ${ }^{65}$ We adopted the method of random sampling to extract 2000 Bootstrap samples from

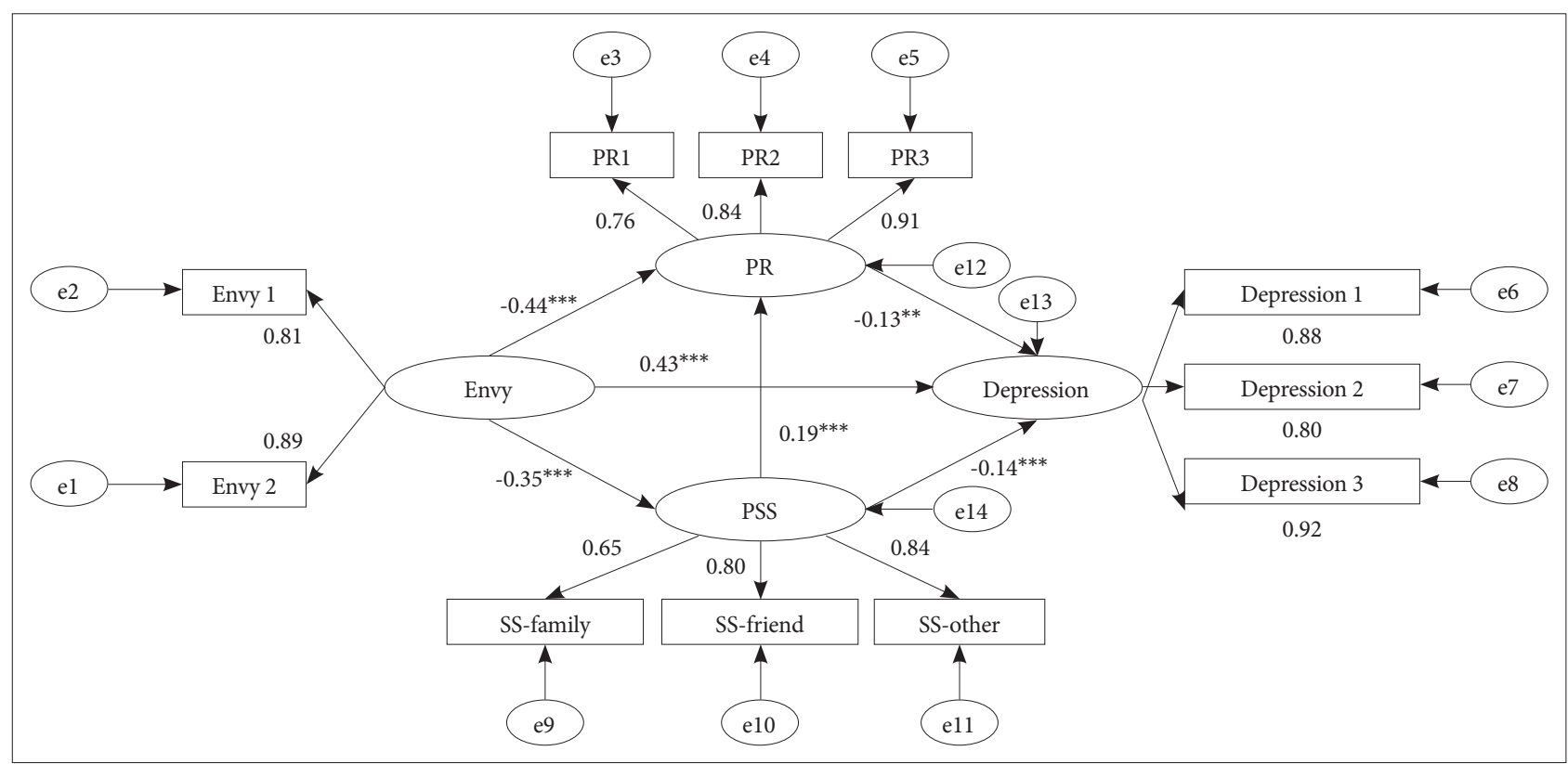

Figure 1. The mediating model factor loadings were standardized. Envy 1 and Envy 2 are two dimensions of the Envy; PR1 and PR2 are two dimensions of the Psychological Resilience (PR); SS-Family, SS-Friend, SS-Other are three subscales of the Perceived Social Support (PSS); Depression1, Depression 2 and Depression 3 are three dimensions of the depression subscales in the 10 dimensions of the multidimensional Symptom Checklist 90 Scale (SCL-90). ${ }^{* *} \mathrm{p}<0.01,{ }^{* * *} \mathrm{p}<0.001$. 
the original data $(n=680)$. The results showed that the mediating variables play an important role in the $95 \%$ confidence interval. As shown in Table 3, envy has a significant effect on depression, both through social support [95\% confidence intervals (0.017-0.095)] and psychological resilience [95\% confidence intervals $(0.015-0.115)]$. In addition, envy has a significant effect on psychological resilience through social support [95\% confidence intervals (-0.060--0.016)] and social support has a significant effect on depression through psychological resilience [95\% confidence intervals (-0.040--0.005)].

\section{Gender differences}

We tested the gender differences between the four latent variables: envy, social support, psychological resilience, and depression. Independent samples t-tests showed that there was no significant difference between men and women on envy $\left[\mathrm{t}_{(680)}=-0.557, \mathrm{p}=0.577\right]$ or depression $\left[\mathrm{t}_{(680)}=-0.327, \mathrm{p}=0.744\right]$. However psychological resilience $\left[\mathrm{t}_{(680)}=2.050, \mathrm{p}=0.041\right]$ and social support had significant gender differences $\left[\mathrm{t}_{(680)}=-2.454\right.$, $\mathrm{p}=0.014]$; psychological resilience was higher in men than women, while the level of social support was higher in women than men. On this basis, we further studied the stability of our structural model.

We used multi-group analysis to ascertain whether there were significant differences in the path coefficients in the transgender model. Referring to the study of Bertera, ${ }^{66}$ we established two models and maintained the stability of basic parameters (factor loadings, error variance, and structural covariance). One allows free estimation of cross-gender paths (unconstrained structural paths), while the other limits path coefficients between two genders (constrained structural paths). The results confirmed significant differences between the two models $\left[\Delta \chi_{(17, \mathrm{n}=680)}^{2}=57.742, \mathrm{p}=0.001\right]$. At the same time, comparing the other parameters in the two models showed that

Table 3. Standardized indirect effects and $95 \%$ confidence intervals

\begin{tabular}{lccc}
\hline \multicolumn{1}{c}{ Pathways } & Estimate & Lower & Upper \\
\hline Envy $\rightarrow$ PSS $\rightarrow$ depression & 0.049 & 0.017 & 0.095 \\
Envy $\rightarrow$ PR $\rightarrow$ depression & 0.057 & 0.015 & 0.115 \\
Envy $\rightarrow$ PSS $\rightarrow$ PR & -0.067 & -0.060 & -0.016 \\
PSS $\rightarrow$ PR $\rightarrow$ depression & -0.025 & -0.040 & -0.005 \\
\hline
\end{tabular}

PSS: perceived social support, PR: psychological resilience both models have a good fit (Table 4). Therefore, multi-group deformation models with limited parameters are generally acceptable. In addition, we further calculated the critical ratio of standard deviation (CRD) to explore the gender differences in specific paths. According to the decision rule, the absolute value of $\mathrm{CRD}$ is greater than 1.96 , which indicates that there is a significant gender difference between the two paths $(p<0.05)$. The results showed significant gender differences in the structural paths from envy to psychological resilience $\left(\mathrm{CRD}_{\mathrm{Envy} \rightarrow \mathrm{PR}}=2.112\right)$. There were also significant gender differences in the structural paths from social support to psychological resilience $\left(\mathrm{CRD}_{\mathrm{PSS} \rightarrow \mathrm{PR}}=3.370\right)$. However, there were no significant gender differences from envy to psychological resilience $\left(\mathrm{CRD}_{\mathrm{Envy} \rightarrow \mathrm{PR}}=0.485\right)$, from psychological resilience to depression $\left(\mathrm{CRD}_{\mathrm{Envy} \rightarrow \mathrm{PSS}}=1.686\right)$, from envy to social support, or from social support to depression $\left(\mathrm{CRD}_{\mathrm{PSS} \rightarrow \text { Depression }}=\right.$ $-0.489)$.

\section{DISCUSSION}

The present study aimed, based on the resilience framework, to explore the mediating roles of social support and psychological resilience between envy and depression. The results confirmed that envy was positively correlated with depression. At the same time, the results showed that there was a significant negative correlation between envy and psychological resilience. Moreover, social support and psychological resilience played significant mediating roles between envy and depression. In addition, the results also showed that envy indirectly positive affect people depression trend by negatively affecting psychological resilience through negatively influencing social support. Thus, all four hypotheses were confirmed.

\section{The relationship between envy and depression}

According to the correlation analysis, there was a significant positive correlation between envy and depression, which verifies hypothesis 1 . People with high levels of envy are more concerned about self-deficiency and other people's possessions and are more likely to experience negative experiences such as inferiority and dejection as a result. ${ }^{4-8,20}$ These feelings may subsequently lead to depression. ${ }^{12}$

Table 4. Unconstrained and constrained structural paths across genders

\begin{tabular}{lccccccc}
\hline & $\chi^{2}$ & df & CFI & RMSEA & SRMR & AIC & ECVI \\
\hline Unconstrained SP & 123.691 & 80 & 0.989 & 0.028 & 0.041 & 227.691 & 0.336 \\
Constrained SP & 181.433 & 97 & 0.979 & 0.036 & 0.057 & 251.433 & 0.371 \\
\hline
\end{tabular}

RMSEA: root-mean-square error of approximation, SRMR: standardized root-mean-square residual, CFI: comparative fit index, AIC: akaike information criterion, ECVI: expected cross-validation index 


\section{The relationship between envy and psychological resilience}

In addition, there was also a negative correlation between envy and psychological resilience, which was confirmed by the regression coefficient in the structural equation model. In other words, higher levels of envy indicated lower levels of psychological resilience, which verifies hypothesis 2. Firstly, envy as a negative personality trait ${ }^{4-8}$ may reduce people's selfefficacy, which was one important positive component of psychological resilience; ${ }^{31}$ thus there was a negative correlation between the two variables.

Secondly, we can explain this result from the perspective of self-esteem. Previous studies have shown a negative correlation between envy and self-esteem; $;{ }^{67,68}$ people generate envy because of an upward social comparison and this threatens their self-esteem. In addition, prior studies have shown that self-esteem and psychological resilience are positively correlated. ${ }^{69}$ Therefore, in the process of upward social comparison, when people feel envy, their self-esteem will be threatened which will negatively impact on their psychological resilience.

\section{The mediating effect of psychological resilience and social support}

In addition, based on Model 1, we found that social support and psychological resilience have significant mediating effects between envy and depression, which verified hypothesis 3 . Meanwhile, this result also verified the resilience framework. When people face negative experiences, their external support environment interacts with their internal psychological resilience to determine their ability to adapt to the negative experience. ${ }^{32}$ Firstly, we shall explain the mediating role of social support between envy and depression. Social support is a supportive resource or supportive behavior, and people who have a good social support system can better maintain a positive emotional experience. ${ }^{39}$ Therefore, people with high envy may perceive less supportive resources or supportive behavior, which in turn increases the tendency to experience depression. Secondly, we explained the mediating role of psychological resilience between envy and depression. Our research showed that envy was negatively correlated with psychological resilience. In addition, the higher the level of psychological resilience, the more positive emotions and strategies of coping with stress the individual has, ${ }^{70,71}$ thus inhibiting the tendency to experience depression. Therefore, people with high envy levels are less likely to adopt positive coping styles, increasing their likelihood of suffering from depression.

Interestingly, based on these two mediation relationships, we also found two other significant mediation relationships in Model 1:1) envy $\rightarrow$ social support $\rightarrow$ psychological resilience; 2 ) social support $\rightarrow$ psychological resilience $\rightarrow$ depression. The results showed firstly that envy decreased psychological resilience through decreasing social support, and secondly that lower levels of social support increased depression tendency through decreasing psychological resilience. Firstly, we explained the mediating role of social support between envy and psychological resilience. Previous studies have shown that the core characteristic of envy is social pain ${ }^{72}$ and it is difficult for people with higher levels of envy to feel social support. ${ }^{16,73}$ In addition, prior studies have shown that social support is positively correlated with psychological resilience. ${ }^{49,50}$ Therefore, high envy people feel as though they receive less social support, which in turn inhibits their level of psychological resilience. Secondly, we explain the mediating role of psychological resilience between social support and depression, which confirms findings from prior studies. ${ }^{17}$ This finding may be attributed to the fact that low social support will lead to less supportive resources and behaviors, ${ }^{39}$ so that people recover from stress more slowly, in turn decreasing their level of psychological resilience, thus enhancing depression. ${ }^{74}$ Based on the above analysis, we combined the results of two significant mediations to obtain a comprehensive path: envy $\rightarrow$ social support $\rightarrow$ psychological resilience $\rightarrow$ depression, which confirmed both hypothesis 4 and the resilience framework. ${ }^{32}$ That is to say, the higher the individual's level of envy, the lower their level of social support which can decrease their psychological resilience by lowering their perceived supportive resources and behaviors, thereby indirectly enhancing their depression.

\section{Gender differences}

In addition, tests of gender differences showed that the psychological resilience level of men was slightly higher than that of women, while the social support level of women was higher than that of men, which was consistent with the results of previous research. Previous studies have shown that men show higher levels of psychological resilience than women. ${ }^{75,76}$ This may be due to the fact that men were more accepting of themselves and those positive tendencies can translate into psychological resilience in their daily life. Likewise, many studies have shown that women have higher levels of social support than men, which may be due to the fact that women have larger and more intimate social networks. ${ }^{16,77,78}$

Moreover, gender differences are also reflected in the structural paths: 1) envy $\rightarrow$ psychological resilience shows that compared with men, women with a high level of envy and a lower level of psychological resilience. The reason for those may be that women have higher levels of envy ${ }^{16}$ and are less likely to recover from adversity and stress, so their level of psychological resilience is lower than that of men. ${ }^{75,76}$ ) social support $\rightarrow$ psychological resilience shows that compared with men, women have higher level of social support and psychological resil- 
ience. Based on gender role theory, women tend to be more compassionate and exhibit more supportive behaviors, ${ }^{79}$ so when confronted with adversities and stress, women tend to adopt positive coping styles, so their level of psychological resilience is higher.

\section{Limitations and future directions}

There are some limitations on this study. Firstly, the sample of our study is Chinese college students. Therefore, the findings of this study may not be extended to other groups. Secondly, the gender distribution of the participants was imbalanced. Although we have conducted a cross gender model analysis, future research should pay attention to ensuring gender balance. What's more, our research uses a self-reporting method, but it has some shortcomings. This method is relatively subjective and prone to personal bias. In the future, experimental methods can be used to explore the relationship between envy and depression and its explanation mechanism.

Remarkably, previous studies have argued that envy can be divided into benign/malicious envy. ${ }^{10}$ According to the nature of envy's motivation, individuals with benign envy will motivate them to improve their position, thereby narrow the difference between themselves and the envied. ${ }^{10,80,81}$ While individuals with malicious envy have a downward motivation, which makes it possible to destroy the advantages of the envied. ${ }^{10,80,82,83}$ In addition, there are differences between the two types of envy in emotional feelings and specific behavioral tendencies. ${ }^{10,80}$ Individuals with malicious envy are tend to perceive hostility, unfairness, and have a stronger tendency to disparage others. ${ }^{5,81,84,85}$ While individuals with benign envy show willing to be close to envied person and tend to have positive thoughts about them. ${ }^{10,80}$ Therefore, it is necessary for future studies to further explore the relationship between benign/ malicious envy and depression and its mechanism. To further expands the understanding of the formation mechanism of depression from the perspective of benign/malicious envy.

\section{Social implications}

The findings of this study have some social implications. Firstly, the current study points out a personality variable, disposition envy, which affects depression, so as to expand the explanation mechanism of depression. Secondly, the current study reveal for the first time that we can intervene the influence of envy on depression from the perspectives of social support and psychological resilience, and then expand the resilience framework theory. Meanwhile, it also provides a new practical perspective of the prevention and correction of depression.

In conclusion, the present study is the first to prove the mediating mechanisms of social support and psychological re- silience between envy and depression, based on the resilience framework. The results showed that envy affects depression in multiple ways. Firstly, envy directly affects individuals' social support and psychological resilience which then impacts their depression. Secondly, envy indirectly affects psychological resilience by affecting social support, which in turn thus indirectly affects depression. Therefore, our study not only provides theoretical support for inhibiting individuals' depression by promoting their social support and psychological resilience, but also has important significance for extending the resilience framework theory.

\section{Acknowledgments}

This work was supported by grants from the project by Hunan Province Philosophy and Social Science Project (18YBA324, Project Name: The Personality Basis of Social Aggression and the Regulation Mechanism of Benign/Malicious Envy).

\section{Conflicts of Interest}

The authors have no potential conflicts of interest to disclose.

\section{Author Contributions}

Study design: Yanhui Xiang. Date analysis: Xia Dong. Paper writing: Xia Dong. Paper revising: all authors.

\section{ORCID iDs}

Yanhui Xiang https://orcid.org/0000-0002-5317-9708

Xia Dong https://orcid.org/0000-0002-2206-4668

Jiaxu Zhao https://orcid.org/0000-0003-4989-4431

\section{REFERENCES}

1. Figueiredo FP, Parada AP, de Araujo LF, Silva WA, Del-Ben CM. The Influence of genetic factors on peripartum depression: a systematic review. J Affect Disord 2015;172:265-273.

2. Mcfarlane AH, Bellissimo A, Norman GR. The role of family and peers in social self-efficacy: links to depression in adolescence. Am J Orthopsychiatry 2010;65:402-410.

3. Bajraktarov S, Gudevanikovska D, Manuševa N, Arsova S. Personality characteristics as predictive factors for the occurrence of depressive disorder. Open Access Maced J Med Sci 2017;5:48-53.

4. Gold BT. Enviousness and its relationship to maladjustment and psychopathology. Pers Indiv Differ 1996;21:311-321.

5. Lange J, Crusius J. Dispositional envy revisited: unraveling the motivational dynamics of benign and malicious envy. Pers Soc Psychol Bull 2015;41:284-294.

6. Lange J, Blatz L, Crusius J. Dispositional Envy: A Conceptual Review. SAGE Handbook of Personality and Individual Differences. Thousand Oaks, CA: SAGE; 2018.

7. Rentzsch K, Gross JJ. Who turns green with envy? Conceptual and empirical perspectives on dispositional envy. Eur J Personality 2015;29: 530-547.

8. Smith RH, Parrott WG, Diener EF, Hoyle RH, Kim SH. Dispositional envy. Pers Soc Psychol Bull 1999;25:1007-1020.

9. Crusius J, Mussweiler T. When people want what others have: the impulsive side of envious desire. Emotion 2012;12:142-153.

10. Van de Ven N, Zeelenberg M, Pieters R. Leveling up and down: the experiences of benign and malicious envy. Emotion 2009; 9:419-429.

11. Smith RH, Kim SH. Comprehending envy. Psychol Bull 2007;133:4664.

12. Smith RH, Parrott WG, Ozer D, Moniz A. Subjective injustice and in- 
feriority as predictors of hostile and depressive feelings in envy. Pers Soc Psychol Bull 1994;20:705-711.

13. Appel H, Crusius J, Gerlach AL. Social comparison, envy, and depression on Facebook: a study looking at the effects of high comparison standards on depressed individuals. J Soc Clin Psychol 2015;34:277-289.

14. Appel H, Gerlach AL, Crusius J. The interplay between Facebook use, social comparison, envy, and depression. Curr Opin Psychol 2016;9:4449.

15. Tandoc EC, Ferrucci P, Duffy M. Facebook use, envy, and depression among college students: Is facebooking depressing? Comput Hum Behav 2015;43:139-146.

16. Xiang Y, Chao X, Ye Y. Effect of gratitude on benign and malicious envy: the mediating role of social support. Front Psychiatry 2018;9:139.

17. Li J, Theng YL, Foo S. Does psychological resilience mediate the impact of social support on geriatric depression? An exploratory study among Chinese older adults in Singapore. Asian J Psychiatry 2015;14:22-27.

18. Wang X, Cai L, Qian J, Peng JX. Social support moderates stress effects on depression. Int J Ment Health Systems 2014;8:41-46.

19. Zyrianova Y, Kelly BD, Gallagher C, Mccarthy C, Molloy MG, Sheehan J. Depression and anxiety in rheumatoid arthritis: the role of perceived social support. Irish J Med Sci 2006;175:32-36.

20. Parrott WG, Smith RH. Distinguishing the experiences of envy and jealousy. J Pers Soc Psychol 1993;64:906-920.

21. Campbell-Sills L, Stein MB. Psychometric analysis and refinement of the connor-davidson resilience scale (CD-RISC): validation of a 10item measure of resilience. J Trauma Stress 2007;20:1019-1028.

22. Kim DH, Yoo IY. Relationship between depression and resilience among children with nephrotic syndrome. J Korean Acad Nurs 2004;34:534540 .

23. Southwick SM, Charney DS. The science of resilience: implications for the prevention and treatment of depression. Science 2012;338:79-82.

24. Gotlib IH, Joormann J. Cognition and depression: current status and future directions. Annu Rev Clin Psychol 2010;6:285-312.

25. Hartlage S, Arduino K, Alloy LB. Depressive personality characteristics: state dependent concomitants of depressive disorder and traits independent of current depression. J Abnorm Psychol 1998;107:349-354.

26. Phillips KA, Gunderson JG, Hirschfeld RM, Smith LE. A review of the depressive personality. Am J Psychiatry 1990;147:830-837.

27. Festinger L. A theory of social comparison processes. Human Relat 1954;7:117-140.

28. Taylor SE, Brown JD. Illusion and well-being: a social psychological perspective on mental health. Psychol Bull 1988;103:193-210.

29. Lam CK, Van der Vegt GS, Walter F, Huang X. Harming high performers: a social comparison perspective on interpersonal harming in work teams. J Appl Psychol 2011;96:588-601.

30. Reid R. Psychological resilience. Medico-Legal J 2016;84:172-184.

31. Connor KM, Davidson JRT. development of a new resilience scale: the Connor-Davidson resilience scale (CD-RISC). Depress Anxiety 2003; 18:76-82.

32. Kumpfer KL. Factors and Processes Contributing to Resilience. Resilience and Development. New York: Springer US; 2002.

33. Wingo AP, Wrenn G, Pelletier T, Gutman AR, Bradley B, Ressler KJ. Moderating effects of resilience on depression in individuals with a history of childhood abuse or trauma exposure. J Affect Disord 2010; 126:411-414.

34. Caprara GV, Vecchione M, Alessandri G, Gerbino M, Barbaranelli C. The contribution of personality traits and self-efficacy beliefs to academic achievement: a longitudinal study. Br J Educ Psychol 2011;81: 78-96.

35. Wang J, Chang C, Yao S, Liang C. The contribution of self-efficacy to the relationship between personality traits and entrepreneurial intention. High Educ 2016;72:209-224.

36. Poole JC, Dobson KS, Pusch D. Childhood adversity and adult depression: the protective role of psychological resilience. Child Abuse Negl 2017;64:89-100.
37. Sharpley CF, Wootten AC, Bitsika V, Christie DR. Variability over time-since-diagnosis in the protective effect of psychological resilience against depression in Australian prostate cancer patients: implications for patient treatment models. Am J Mens Health 2013;7:414-422.

38. Cobb S. Social support as a moderator of life stress. Psychosom Med 1976;38:300-314.

39. Lia X, Huang XT. Social support and its mechanism for mental health. Psychol Res 2010;3:3-8.

40. Moran S, Schweitzer ME. When better is worse: envy and the use of deception. Negot Conflict Manag Res 2008;1:3-29.

41. Hofer J, Busch H. When the needs for affiliation and intimacy are frustrated: envy and indirect aggression among German and Cameroonian adults. J Res Pers 2011;45:219-228.

42. Cohen S, Wills TA. Stress, social support, and the buffering hypothesis. Psychol Bull 1985;98:310-357.

43. Almeida J, Subramanian SV, Kawachi I, Molnar BE. Is blood thicker than water? Social support, depression and the modifying role of ethnicity/nativity status. J Epidemiol Commun Health 2011;65:51-56.

44. Frasure-Smith N, Lespérance F, Gravel G, Masson A, Juneau M, Talajic $\mathrm{M}$, et al. Social support, depression, and mortality during the first year after myocardial infarction. Circulation 2000;101:1919-1924.

45. Cairney J, Boyle M, Offord DR, Racine Y. Stress, social support and depression in single and married mothers. Soc Psychiatry Psychiatr Epidemiol 2003;38:442-449.

46. Jenkins SR, Belanger A, Connally ML, Boals A, Durón KM. First-generation undergraduate students' social support, depression, and life satisfaction. J Coll Couns 2013;16:129-142.

47. Väänänen JM, Marttunen M, Helminen M, Kaltiala-Heino R. Low perceived social support predicts later depression but not social phobia in middle adolescence. Health Psychol Behav Med 2014;2:1023-1037.

48. Berkman LF, Blumenthal J, Burg M, Carney RM, Catellier D, Cowan $\mathrm{MJ}$, et al. Effects of treating depression and low perceived social support on clinical events after myocardial infarction: the Enhancing Recovery in Coronary Heart Disease Patients (ENRICHD) Randomized Trial. JAMA 2003;289:3106-3116.

49. Ai H, Hu J. Psychological resilience moderates the impact of social support on loneliness of "left-behind" children. J Health Psychol 2016;21: 1066-1073.

50. Li W, Sun J. The mental health status of retired old people and its relationship with social support and psychological resilience. Chin Gen Pract 2014;17:1898-1901.

51. Xiang YH, Zhao JX, Li QY, Dong X, Zhao JJ, Zhang WR. Effect of core self evaluation on mental health symptoms among Chinese college students: the mediating roles of benign and malicious envy. Psychiatr Ann 2019;49:277-284

52. Xiang YH, Chen ZY, Zhao JX. How childhood maltreatment impacts aggression from perspectives of social comparison and resilience frame work theory. J Aggress Maltreat T 2019;1-12.

53. Xiang Y, Wang W, Guan F. The relationship between child maltreatment and dispositional envy and the mediating effect of self-esteem and social support in young adults. Front Psychol 2018;9:1054.

54. Zhao J, Peng X, Chao XM, Xiang YH. Childhood maltreatment influences mental symptoms: the mediating roles of emotional intelligence and social support. Front Psychiatry 2019;10:415.

55. Xiang YH, Kong F, Wen X, Wu QH, Mo L. Neural correlates of envy: regional homogeneity of resting-state brain activity predicts dispositional envy. Neuroimage 2016;142:225-230.

56. Zimet GD, Powell SS, Farley GK, Werkman S, Berkoff KA. Psychometric characteristics of the Multidimensional Scale of Perceived Social Support. J Pers Assess 1990;55:610-617.

57. Kong F, Zhao J, You X. Emotional intelligence and life satisfaction in Chinese university students: the mediating role of self-esteem and social support. Pers Indiv Differ 2012;53:1039-1043.

58. Kong F, Wang X, Hu SY, Liu J. Neural correlates of psychological resilience and their relation to life satisfaction in a sample of healthy young 
adults. NeuroImage 2015;123:165-172.

59. Derogatis LR, Lipman RS, Covi L. SCL-90: an outpatient psychiatric rating scale--preliminary report. Psychopharmacol Bull 1973;9:13-28.

60. Tang Q, Cheng Z. The use and reanalysis of SCL-90 in China. Chin J Clin Psychol 1999;7:16-20.

61. Little TD, Cunningham WA, Shahar G, Widaman KF. To parcel or not to parcel: exploring the question, weighing the merits. Struct Equ Modeling 2002;9:151-173.

62. Byrne BM. Structural equation modeling with AMOS, EQS, and LISREL: comparative approaches to testing for the factorial validity of a measuring instrument. Int J Testing 2001;1:55-86.

63. Akaike H. Factor analysis and AIC. Psychometrika 1987;52:317-332.

64. Browne MW, Cudeck R. Alternative ways of assessing model fit - Institute for Social and Economic Research (ISER). Clin Diagn Lab Immun 1992;7:161-167.

65. Fritz MS, MacKinnon DP. Required sample size to detect the mediated effect. Psychol Sci 2007;18:233-239.

66. Bertera EM. Mental health in US adults: the role of positive social support and social negativity in personal relationships. J Soc Pers Relat 2005;22:33-48.

67. Duarte JL. The Effects of Scarcity and Self-esteem on the Experience of Envy. Tempe: Arizona State University; 2011.

68. Yu Z, Hao J, Shi B. Dispositional envy inhibits prosocial behavior in adolescents with high self-esteem. Pers Indiv Differ 2018;122:127-133.

69. Liu Y, Wang Z, Zhou C, Li T. Affect and self-esteem as mediators between trait resilience and psychological adjustment. Pers Indiv Differ 2014;66:92-97.

70. Southwick SM, Vythilingam M, Charney DS. The psychobiology of depression and resilience to stress: implications for prevention and treatment. Annu Rev Clin Psychol 2005;1:255-291.

71. Ong AD, Bergeman CS, Bisconti TL, Wallace KA. Psychological resilience, positive emotions, and successful adaptation to stress in later life. J Pers Soc Psychol 2006;91:730-749.

72. Tai K, Narayanan J, McAllister DJ. Envy as pain: rethinking the nature of envy and its implications for employees and organizations. Acad
Manage Rev 2012;37:107-129.

73. Sherbourne CD, Stewart AL. The MOS social support survey. Soc Sci Med 1991;32:705-714.

74. Toukhsati SR, Jovanovic A, Dehghani S, Tran T, Hare DL. Low psychological resilience is associated with depression in patients with cardiovascular disease. Eur J Cardiovasc Nur 2017;16:64-69.

75. Boardman JD, Blalock CL, Button TM. Sex differences in the heritability of resilience. Twin Res Hum Genet 2008;11:12-27.

76. Masood A, Masud Y, Mazahir S. Gender differences in resilience and psychological distress of patients with burns. Burns 2016;42:300-306.

77. Kendler KS, Myers J, Prescott CA. Sex differences in the relationship between social support and risk for major depression: a longitudinal study of opposite-sex twin pairs. Am J Psychiatry 2005;162:250-256.

78. Antonucci TC, Akiyama H. Social networks in adult life and a preliminary examination of the convoy model. J Gerontol 1987;42:519-527.

79. Zelezny LC, Chua PP, Aldrich C. New ways of thinking about environmentalism: Elaborating on gender differences in environmentalism. J Soc Issues 2000;56:443-457.

80. Van de Ven N, Zeelenberg M, Pieters R. Appraisal patterns of envy and related emotions. Motiv Emot 2012;36:195-204.

81. Crusius J, Lange J. What catches the envious eye? Attentional biases within malicious and benign envy. J Exp Soc Psychol 2014;55:1-11.

82. Navarro-Carrillo G, Beltrán-Morillas AM, Valor-Segura I, Expósito F. The pernicious effects of malicious versus benign envy: perceived injustice, emotional hostility and counterproductive behaviors in the workplace. Span J Psychol 2018;21:E41.

83. Van de Ven N, Hoogland CE, Smith RH, Van Dijk WW, Breugelmans $\mathrm{SM}$, Zeelenberg M. When envy leads to schadenfreude. Cogn Emot 2015;29:1007-1025.

84. Lange J, Paulhus DL, Crusius J. Elucidating the dark side of envy: distinctive links of benign and malicious envy with dark personalities. Pers Soc Psychol Bull 2018;44:601-614.

85. Lange J, Weidman AC, Crusius J. The painful duality of envy: evidence for an integrative theory and a meta-analysis on the relation of envy and schadenfreude. J Pers Soc Psychol 2018;114:572-598. 